\title{
Vertical Integration and Competition Between Networks
}

\author{
CATHERINE C. DE FONTENAY
}

Melbourne Business School and Department of Economics, University of Melbourne

JOSHUA S. GANS *

Melbourne Business School, University of Melbourne

\begin{abstract}
This paper provides a simple model of bargaining and integration within a network and considers how intra-network structure is impacted on by competition between networks. Apart from its analytical tractability, our model demonstrates how integration can be used strategically to redistribute network profits from downstream firms to upstream providers of network services. It also demonstrates that increased inter-network competition can mitigate incentives for inefficient integration.
\end{abstract}

\section{Introduction}

Many industries involve two networks competing with one another. In some cases, these networks are interconnected with one another as well as engaged in competition for subscribers; for example, mobile and fixed line telephony and electricity distribution. In other cases, the networks involve a number of participants who deliver value to customers and who compete for customers with participants in a distinct network. An example of this type of network occurs in Internet service provision where a number of ISPs operate off a shared backbone network. These ISPs compete directly with other ISPs on other backbones with a critical element of their competition being the terms and conditions of the access arrangements between the ISPs and their backbone network. ${ }^{1}$ These arrangements are in some cases conducted at arms length but in other with more integrated structures - with the

\footnotetext{
* All correspondence to Joshua Gans, Melbourne Business School, 200 Leicester Street, Carlton Victoria 3053 Australia. E-mail: J.Gans@unimelb.edu.au. Parts of this paper were previously circulated under the title "Extending Market Power through Vertical Integration." The authors would like to thank Stephen King, Jeff Zwiebel and an anonymous referee for helpful comments. Responsibility for all errors remains our own. ${ }^{1}$ This is also the structure that has evolved in mobile internet provision where content providers are located on a particular mobile network and in some cases can provide services to subscribers on a competing mobile network (see Kim, Kwark and Lee, 2004).
} 
upstream backbone owning its own downstream retail providers. It is this type of network that is the focus of this paper. ${ }^{2}$

Most analyses of vertical integration focus on the case of a single bottleneck monopolist located upstream that vertically integrates into downstream segments. ${ }^{3}$ Where issues of competition and its impact on integration are considered, models are constructed that treat upstream competitors as highly asymmetric in their competitive advantages and also as to whether they can integrate or not (for example, Hart and Tirole, 1990). For this reason, it is still an open research question whether concerns regarding vertical integration in the monopoly case extend to situations where the upstream sector is imperfectly competitive as occurs in many network industries.

The purpose of this paper is to provide a model of vertical integration when there is an upstream oligopoly in order to examine (1) whether such vertical integration can be considered anti-competitive; (2) whether vertical integration decisions of upstream firms are related; and (3) whether increasing upstream competition can improve the efficiency of integration decisions. In so doing, we assume that upstream firms are symmetric both in their abilities to compete as well as in their abilities to integrate. Moreover, to avoid issues that arise from double marginalisation, we focus on the case where upstream firms negotiate with their downstream purchasers over a quantity and lump-sum transfer. We assume such negotiations are bilateral so as to avoid any nakedly collusive effect from supply negotiations.

We demonstrate here that many of the concerns for vertical integration in the monopoly context do indeed carry over to the imperfectly competitive case. Specifically, vertical integration will deter downstream entry and cause supply prices to rise. Moreover, when networks compete, there is more likely to be vertical integration within one network if other networks are vertically integrated. This, however, does not happen because of concerns over supply or demand assurance (see de Fontenay and Gans, 2003) but instead because of how vertical integration alters the nature of competition between networks.

The outline for the paper is as follows. In section 2 , we set up the model structure focussing on the case of an upstream firm selling to a number of downstream firms. To determine prices ex post, in Section 3, we model the multi-agent bargaining game using the framework of Stole and Zwiebel (1996a, 1996b) which applies naturally in the vertical supply environment we consider here. This bargaining involves the upstream firm sequentially approaching independent downstream firms to negotiate over supply or access terms. A key feature of the model is that such terms are subject to renegotiation if either upstream or downstream firms believe that such renegotiation can improve their payoff. In a network environment this means that negotiated outcomes will only be an equilibrium if renegotiation is not chosen by any party, either in response to changes in the structure of their own network or changes in the nature of competition with other networks.

In section 4, we demonstrate that, without integration, industry output exceeds levels that would arise if networks were constructed to maximise network profits and that integration results in a reversion towards that level. Importantly, as the level of upstream competition increases, integration - assumed here to be mildly inefficient - is less likely to

\footnotetext{
${ }^{2}$ Thus, we are not specifically addressing situations where there are network externalities, two-sided networks or situations where downstream firms can trade with more than one upstream firm. Those situations pose significant analytical difficulties some of which are addressed in de Fontenay and Gans (2004b). The present paper describes vertical integration in something more akin to a sales or distribution network.

${ }^{3}$ See Rey and Tirole (forthcoming) for a review of this literature.
} 
occur. Thus, increased network competition both improves competitive outcomes overall as well as alleviating productive inefficiencies that might arise from inefficient strategic vertical integration. We also demonstrate that the usual equivalence of closed and open access regimes carries over to this bargaining environment and that there are no incentives for pre-emptive integration in this setting. A final section concludes offering implications for competition regulators.

\section{Basic set-up}

We consider the case of upstream oligopolists $(U i), i \in\{1, \ldots, M\}$, each of whom sells a necessary input to downstream producers. ${ }^{4}$ Associated with each $U i$ are $N_{i}$ downstream firms, $I_{i}$ of whom may be integrated with it. For simplicity, we assume that upstream firms face no production costs and each produces an input a unit of which can be converted by downstream firms into a unit of the final good. The goods produced downstream are perfect substitutes in the eyes of consumers (regardless of their supply source), so that if downstream firms produce a total quantity, $Q$, this results in a market price of $P(Q)$. At times, in order to generate closed form solutions and sort out more complex effects we will focus on the linear and perfectly homogenous demand case in which $P=A-\sum_{i=1}^{M} N_{i}$.

This structure mirrors that of many network industries. For instance, many ISPs build their own systems to operate with a particular backbone network. In effect, the ISPs deal directly with final customers and pay for access to the backbone network. A similar structure occurs for telecommunications retailers who re-sell local or mobile calls. To this end, we assume that it is difficult for downstream firms, following entry, to switch to an alternative upstream provider. For this reason, we will refer to the group of upstream provider and constituent downstream firms as a 'network'.

Consistent with this, we also assume that downstream firms have limited capacity; for simplicity, they can produce at most one unit of the final good. There are no additional marginal costs associated with producing that unit other than those arising from payments upstream. There are, however, fixed costs, $\theta$, incurred by each downstream firm. ${ }^{5}$ These fixed costs represent the opportunity cost for a downstream firm in committing their capacity to the network.

The focus in this paper is on the strategic effects of vertical integration within networks. To isolate such effects, we assume away efficiency reasons for integration, by supposing it to be mildly inefficient. Then an upstream firm will only integrate for strategic reasons. A vertically integrated downstream firm is assumed to face an additional fixed cost, $\Delta>0$, but is otherwise as efficient as non-integrated firms. While we treat this cost as exogenous here, it would be possible to interpret it as indicative of the notion that firms' incentives to undertake effort - or non-contractible investment more generally - are diminished by integration (as in Williamson, 1985). To emphasise, the role of this

\footnotetext{
${ }^{4}$ Our model could equally be applied to the situation where downstream duopolists (that is, duopsonists) bargained with upstream suppliers and considered integrating with them. The basic effects and incentives we consider here would apply in this case (see de Fontenay and Gans, 2004a).

${ }^{5}$ Where relevant we assume that $A>\theta$.
} 
assumption is to provide a minimal specification that rules out integration for anything other than strategic reasons.

Let $\pi\left(N_{i} ; N_{-i}\right)=P\left(N_{i} ; N_{-i}\right)-\theta$ be the profit of a non-integrated downstream firm gross of any upstream input supply price; with $\pi\left(N_{i} ; N_{-i}\right)-\Delta$ the profits of an integrated downstream unit; where $N_{-i}=\sum_{j \neq i} N_{j}$. The profit accruing to a network is $\Pi\left(N_{i} ; N_{-i}\right)-\Delta I_{i}=N_{i} \pi\left(N_{i} ; N_{-i}\right)-\Delta I_{i}$.

An important feature of this paper is the bargaining game within each network. In particular, we do not simply assume that upstream firms can make take-it-or-leave-it offers to affiliated downstream firms. Instead, they must negotiate with each firm individually and further entry by downstream firms is not possible once bargaining has commenced. Our conception here is of an environment in which downstream firms enter into production far less frequently than prices are renegotiated (as a simplification, they are assumed only to enter once). Therefore, given an initial entry of downstream firms, input supply terms can be renegotiated at any time.

Specifically, the bargaining game has the following stages:

(1) (Market Structure) Each Ui chooses the number of integrated units in its network and for each $U i, N_{i}-I_{i}$ independent downstream firms enter to be supplied by $U i$.

(2) (Bargaining) Each $U i$ engages each of its available independent firms in one-on-one negotiations over the input supply contract. This bargaining takes the non-binding form as specified by Stole and Zwiebel (1996a, 1996b).

(3) (Competition) Production and downstream competition occur and payoffs are realised.

In stage 1, the market structure of each network is determined both in terms of the number of independent firms who freely enter and in terms of the number of integrated units that are set up. The key assumption here is that these decisions happen simultaneously. ${ }^{6}$ One important consequence of this is that while downstream entry is possible at the beginning of the game, this cannot be contracted at stage 1 nor revisited at stage 2 - although, as we will demonstrate, upstream firms may not serve all entrants. Essentially, from the upstream perspective, the initial set of firms (including expanding the number it has integrated) cannot be replaced. This gives those firms some hold-up power. Nonetheless, our specification effectively assumes that entry into a network at that stage is not costly. This simplification helps us to emphasise the important role played by difficulties in expanding the number of downstream firms ex post. ${ }^{7}$

Stage 2 bargaining over input prices takes place in a similar manner to the wage bargaining modelled by Stole and Zwiebel (1996a, 1996b), hereafter SZ. The upstream provider and downstream firm bargain bilaterally over input prices in sequential

\footnotetext{
${ }^{6}$ An alternative would be to have the number of integrated units being determined pre-emptively. We discuss this below. However, it is difficult to imagine situations where integration is not possible ex post. If this is the case, the assumed simultaneous determination is the natural specification.

${ }^{7}$ Below we will identify the implications for our results when productive assets are costly to bring into the industry.
} 
transactions. ${ }^{8}$ Long-term price and supply agreements are not possible; in the motivating telecommunications examples these do not occur. So we look for solutions that are stable in the sense that there is no desire on the part of either the upstream firm or the individual downstream firm to exercise their respective abilities to renegotiate supply contract terms. ${ }^{9}$ While it is possible for different firms to pay different prices, given the symmetry between them, this does not occur in equilibrium.

\section{$3 \quad$ Bargaining outcomes within a network}

We will work backwards and consider bargaining within a single network; taking the available downstream firms $\left\{N_{i}, I_{i}\right\}_{i=1}^{M}$ as given. The equilibrium involving the endogenous determination of these will be considered in Section IV.

One advantage of assuming that downstream firms produce at most one unit of output is that it is very close to the SZ context of a firm bargaining with many workers, who can produce a unit of labor or exit negotiations. In their model, negotiations are sequential and bilateral; as a consequence, the solution is not necessarily within the bargaining core. They assume that the cost of bargaining is that negotiations might exogenously break down with some infinitesimal probability. Binmore, Rubinstein and Wolinsky (1986) demonstrated that two agents, bargaining under an infinitesimal risk of breakdown, agree on the Nash bargaining outcome; namely, that each agent receives the same benefit from agreement (where benefit is measured as the gain over what the agent would earn in the event of a breakdown in bargaining). Negotiations can be reopened at any time, and are reopened if any agent believes they can improve their own payoff. ${ }^{10}$

As in any model of bargaining, an important driving force is the outside options of each negotiating agent. For individual downstream firms, if they fail to secure supply of the input, they are able to recover their fixed costs, $\theta$. For an upstream firm, when negotiations with an individual firm break down, in addition to not being able to supply that firm, it must also renegotiate pricing arrangements with other firms and may face a competitive response from the rival network. So a breakdown involves an inframarginal effect, altering an upstream firm's outside option.

To see this, suppose that $U 1$ has $I_{1}$ integrated units. Consider $U 1$ negotiating with a single firm only over the supply price for a unit of the input, $\tilde{p}_{1}\left(1, I_{1} ; N_{-1}\right)$. If negotiations break down, it receives $I_{1}\left(\pi\left(I_{1}, N_{-1}\right)-(\theta+\Delta)\right)$, while the downstream firm avoids costs $\theta$. If supply takes place, the downstream firm earns profits of $\pi\left(1+I_{1} ; N_{-1}\right)=P\left(1+I_{1} ; N_{-1}\right)-\theta$. Splitting the surplus means that $\tilde{p}_{1}\left(1, I_{1} ; N_{2}\right)=\frac{1}{2}\left(\left(I_{1}+1\right) \pi\left(1+I_{1} ; N_{-1}\right)-I_{1} \pi\left(I_{1} ; N_{-1}\right)\right)$.

\footnotetext{
${ }^{8}$ Note that the restriction to bilateral bargaining is consistent with anti-trust laws that prevent horizontal associations that may cause reductions in competition.

${ }^{9}$ As is demonstrated in de Fontenay and Gans (2004b), the model could easily be re-cast as one where parties negotiate contracts contingent upon the state of the network. We adopt the renegotiation concept here to simplify notation.

${ }^{10}$ In point of fact, SZ restrict the opportunities for renegotiation in the bargaining process to show that their results require very limited renegotiation. The results hold when more opportunities for renegotiation exist.
} 
In contrast, consider the case when the upstream firm supplies two firms. Each firm bargains bilaterally with the upstream firm. Nash bargaining implies that each firm splits the surplus created by the relationship - but what is that surplus? Part of the benefit to the upstream firm of supplying a second firm is that it reduces the bargaining power of the first firm. And if negotiations break down with one of the two firms, the upstream firm must renegotiate with the remaining firm, who then receives $\pi\left(1+I_{1} ; N_{-1}\right)-\tilde{p}_{1}\left(1, I_{1} ; N_{-1}\right)$, as above. Thus, we obtain the price $\tilde{p}_{1}\left(2, I_{1} ; N_{-1}\right)$ paid by each of the two firms by equating the benefit to $U 1$ and to a downstream firm:

$$
\begin{array}{r}
\underbrace{2 \tilde{p}_{1}\left(2, I_{1} ; N_{-1}\right)+I_{1} \pi\left(2+I_{1} ; N_{-1}\right)-\left(\tilde{p}_{1}\left(1, I_{1} ; N_{-1}\right)+I_{1} \pi\left(1+I_{1} ; N_{-1}\right)\right)}_{\text {Benefits to U1 } 1} \\
=\underbrace{\pi\left(2+I_{1} ; N_{-1}\right)-\tilde{p}_{1}\left(2, I_{1} ; N_{-1}\right)}_{\text {Benefits to a Downstream Firm }}
\end{array} .
$$

For the case of $N_{1}$ downstream firms, the same recursive structure applies: one benefit of supplying the $N_{1}{ }^{\text {th }}$ additional firm is the amount by which it increases the payments from the remaining $\left(N_{1}-I_{1}-1\right)$ firms. In the technical appendix, we derive the payoff accruing to $U 1$ :

(1)

$$
\left(N_{1}-I_{1}\right) \tilde{p}_{1}\left(N_{1}, I_{1} ; N_{-1}\right)+I_{1}\left(\pi\left(N_{1} ; N_{-1}\right)-\Delta\right)=\frac{1}{N_{1}+1-I_{1}} \sum_{i=I_{1}}^{N_{1}} \Pi\left(i ; N_{-1}\right)-\Delta I_{1} \cdot{ }^{11}
$$

This payoff can also be derived for a situation where the set of downstream firms is a continuum, $\left[0, N_{1}\right]$; producing a total of $N_{1}$ units:

(2) $v\left(N_{1}, I_{1}, N_{-1}\right)=\frac{1}{N_{1}-I_{1}} \int_{I_{1}}^{N_{1}} \Pi\left(i, N_{-1}\right) d i-\Delta I_{1}$

where $v($.$) denotes the payoff function of an upstream firm. Note that under the linear$ demand assumption:

$$
v\left(N_{1}, I_{1} ; N_{-1}\right)=\frac{1}{6}\left(\left(3\left(A-\theta-N_{-1}\right)-2 N_{1}\right)\left(I_{1}+N_{1}\right)-2 I_{1}^{2}\right)-\Delta I_{1}
$$

This result is possible because bargaining power rests on inframarginal effects (the change in the supply price) rather than the marginal effect of any individual firm. Hence, downstream firms have some hold-up power even in the continuous case. For clarity of presentation, we will assume that the pool of downstream firms is a continuum for the remainder of this paper. ${ }^{12}$

\footnotetext{
${ }^{11} \mathrm{SZ}$ demonstrate the robustness of results based on their bargaining mechanisms by considering the outcomes in alternative environments. For example, they allow for asymmetric ex post bargaining power, and heterogeneous agents. They also demonstrate that this bargaining mechanism yields payoffs for agents that are their Shapley values in the corresponding cooperative game. Shapley values have long held intuitive appeal in normative work on bargaining.

${ }^{12}$ All of the qualitative results below hold for the discrete case.
} 


\section{$4 \quad$ Market structure and integration}

We now turn to consider equilibrium in the stage 1 game where downstream firms choose to enter or not and each upstream firm chooses the number of its integrated downstream affiliates. To provide a benchmark for comparison we begin with the 'no integration' case before turning to the equilibrium when integration is possible.

\subsection{No integration equilibrium}

The equilibrium outcome when there are no integrated units can be easily characterised. In a free entry equilibrium, firms will enter to be supplied by a particular network, say 1, up to the point, $\tilde{N}_{1}$, where $\tilde{p}\left(\tilde{N}_{1} ; N_{-1}\right)=\pi\left(\tilde{N}_{1} ; N_{-1}\right)$. This, in turn, implies that $v\left(\tilde{N}_{1} ; N_{-1}\right)=\Pi\left(\tilde{N}_{1} ; N_{-1}\right)$; upstream firms appropriate any industry rents. It is easy to see that the implied level of output exceeds that which would arise if $N_{1}$ was chosen collusively to maximise $\Pi\left(N_{1} ; N_{-1}\right)$. Specifically, for the linear demand case, $\tilde{N}_{1}=\frac{3}{4}\left(A-N_{-1}-\theta\right)$ whereas the number of downstream firms that would maximise network profits would be $\hat{N}_{1}=\frac{1}{2}\left(A-N_{-1}-\theta\right)$; the level of output that would be chosen by a neoclassical firm in Cournot competition.

Turning now to the equilibrium outcomes, due to symmetry, $\tilde{N}_{i}$ as defined by:

$$
\tilde{p}\left(\tilde{N}_{i} ;(M-1) \tilde{N}_{i}\right)=\pi\left(\tilde{N}_{i},(M-1) \tilde{N}_{i}\right) \Rightarrow \frac{1}{\tilde{N}_{i}} \Pi\left(\tilde{N}_{i},(M-1) \tilde{N}_{i}\right)=\frac{1}{\tilde{N}_{i}^{2}} \int_{0}^{\tilde{N}_{i}} \Pi\left(i,(M-1) \tilde{N}_{i}\right) d i
$$

exceeds $\hat{N}_{i}$ as defined by $\Pi^{\prime}\left(\hat{N}_{i} ;(M-1) \hat{N}_{i}\right)=0$; the Cournot oligopoly outcome. Specifically, for our running case:

$$
\tilde{N}_{i}=\frac{3}{1+3 M}(A-\theta)>\hat{N}_{i}=\frac{1}{1+M}(A-\theta) \text {. }
$$

In effect, when downstream firms have some ex post bargaining power, this means that market structure will be more competitive than in the usual Cournot case where upstream firms have all of the bargaining power in dictating supply terms downstream. This outcome mirrors the case where there is a monopoly bottleneck (see de Fontenay and Gans, 2004a) and downstream firms have some bargaining power. In each case, market structure is more competitive than would arise under a standard neoclassical benchmark.

\subsection{The incentive to integrate}

Before examining the full integration equilibrium, it is useful to examine the incentives of a given upstream firm to integrate within its own network. As noted above, free entry tends to reduce the bargaining power of downstream firms. When there are few of them, the upstream firm is on the steeply rising portion of its profit function. Free entry moves it to a downward-sloping portion of that function. Indeed, at that point the marginal productivity of each downstream firm is negative and the bargaining power of the first few is much attenuated. 
Nonetheless, the overproduction caused by free entry is a particularly costly means of reducing the bargaining power of downstream firms. In contrast, if the monopolist were to have some integrated downstream units, thereby avoiding hold-up issues associated with renegotiation with those units, it would never face a situation (after multiple breakdowns in negotiations) of having to negotiate with just a few firms on a steep portion of its profit function. In effect, by acquiring units, the upstream firm ensures some demand that independents can never threaten to remove. This, in turn, impacts upon the returns to entry; effectively deterring entry by independent firms.

Intuitively, one would expect that the profitability of integration is higher, the lower are the costs of integration, $\Delta$. The following proposition confirms this.

Proposition: Suppose $N_{-i}$ is fixed. Let $\tilde{N}_{i}\left(I_{i}\right)$ be the free-entry number of downstream firms and $\tilde{p}\left(\tilde{N}_{i}\left(I_{i}\right), I_{i}\right)$ the resulting prices to independent firms. $U_{i}$ 's integration choice is as follows:

a) for $\Delta=0$, there is complete integration, $\tilde{I}_{i}=\tilde{N}_{i}\left(=\hat{N}_{i}\right)$

b) for $0<\Delta<\tilde{p}\left(\tilde{N}_{i}(0), 0\right)$, there is partial integration, $0<\tilde{I}_{i}<\tilde{N}_{i}$

c) for $\Delta \geq \tilde{p}\left(\tilde{N}_{i}(0), 0\right)$, there is no integration, $\tilde{I}_{i}=0$ (and $\left.\tilde{N}_{i}=\tilde{N}_{i}(0)\right)$.

The proof is in the appendix. The proposition shows that partial integration is an equilibrium when the costs of integration $(\Delta)$ are small, and full integration when there are no such costs. When these costs are zero, complete integration is worthwhile as upstream firms do not face a hold-up problem and independent entry is deterred. They do not need to expand production to reduce the bargaining power of independent firms. However, when $\Delta$ exceeds average profits without integration, it is never worthwhile to integrate. This is because integration recovers the hold-up value of an individual firm. At the optimal $N_{i}$, this is simply average profits.

Basically, integration allows each upstream firm to negotiate higher supply prices to independent downstream firms (de Fontenay and Gans, 2004a). This in turn reduces the total number of independents who enter. First, the integrated capacity substitutes partly for that of independents. Second, and most importantly, the presence of integrated units diminishes the bargaining position of independents. This effect is so strong that over the range where integration is an equilibrium (that is, where the cost of integration is not too high), it can be shown that the number of independents falls by more than the increase in integrated firms, and therefore the total number of downstream firms falls.

It is worth noting that the basic strategic effect here (that integration allows an upstream firm to both improve its bargaining power and generate a more concentrated market structure downstream) would be preserved even if downstream firms were not capacity constrained and could produce many units but otherwise had quasi-convex costs. In this situation, however, the relative bargaining position of downstream firms would be worse because, in the event of a disagreement, an upstream firm could expand its supply to remaining downstream firms. In addition, if integrated firms were relatively less efficient at the margin, then with variable quantities, integrated firms' production could be limited in equilibrium with upstream firms using the threat of expanding their output only in the event of a disagreement with independent firms. However, relaxing the assumption of variable quantities would re-introduce the contracting externalities emphasized by Rey and 
Tirole (forthcoming); complicating the analysis by introducing additional strategic motives for integration, while otherwise preserving the strategic effect we have identified here. ${ }^{13}$

Finally, it is worth examining how the incentive to integrate changes with the integration choices by other upstream firms. Notice that the choices of the other networks interact with $U i$ 's payoff only through downstream demand. In particular, as $N_{-i}$ rises, so long as $P_{12} \leq 0$, it reduces the marginal incentive to expand output and the marginal return to integration (see the appendix for a proof).

Thus, the converse holds true for an increase in $I_{-i}$, which will reduce $N_{-i}$, as we have seen. A competitor's decision to integrate increases the returns to expanding output and integrating. This implies that each upstream firms' choice of integration are strategic complements. Fundamentally, the reason is that a competitor who integrates reduces its output, leaving the firm with higher effective demand and higher profits. But at the same time as profits increase, so does the bargaining power of downstream firms, and therefore the distortion in $N_{i}$ and $I_{i}$ increases as well.

\subsection{Integration equilibrium}

As noted above, holding the market structure of other networks as given, each upstream firm has an incentive to integrate and these incentives are complementary. Under symmetry, this means that, in equilibrium, integration will occur if it is not too costly, and it will result in a reduction in network and total output in the market.

To see this, we focus on the linear demand case. In this situation,

$$
\tilde{N}_{i}=\min \left[\frac{A-\theta+2 \Delta}{1+M}, \frac{3(A-\theta)}{1+3 M}\right] \text { and } \tilde{I}_{i}=\max \left[0, \frac{A-\theta-(1+3 M) \Delta}{1+M}\right]
$$

Therefore, $Q=\min \left[\frac{M}{1+M}(A-\theta+2 \Delta), \frac{3 M}{1+3 M}(A-\theta)\right]$ compared with $\frac{M}{1+M}(A-\theta)$ under Cournot duopoly when upstream firms have all the bargaining power. Critically, when integration is not too costly, industry output is lower and prices are higher than when no integration is permitted.

It is useful to note, however, that increased upstream competition, as well as expanding industry output in equilibrium, also reduces the inefficiency that can be 'tolerated' for integration to remain profitable. That is, integration will only be profitable if:

(4) $\Delta \leq \frac{1}{1+3 M}(A-\theta)$

Notice that the right hand side of (4) is decreasing in $M$. Thus, for a strictly positive $\Delta$, zero integration is chosen as $M$ gets large and rises above $\frac{A-\theta-\Delta}{3}$. In the limit, as upstream competition continues to increase, outcomes become perfectly competitive, as in Cournot competition.

\footnotetext{
${ }^{13}$ Chemla (2003) does consider a Rey and Tirole type effect as well as a negotiation effect similar to that in this paper, but does not allow for upstream competition. Our framework here provides a more complete specification of the nature of multilateral bargaining, which allows us to study network competition.
} 


\subsection{What if upstream firms can deny access?}

The above results rely on the notion that any independent firm who enters can negotiate for supply terms with an upstream firm. This is akin to an open access regime without regulated pricing terms. Given the increased competition such entry generates it is useful to note that if upstream firms can exclude access and deny independent firms supply, the same outcome results.

In SZ and de Fontenay and Gans (2004a) the upstream firm can choose or designate its downstream affiliates prior to any negotiations beginning. In such a closed access regime, $\tilde{N}_{i}$ would be chosen to maximise Ui's payoff, $v\left(N_{i}, I_{i} ; N_{-i}\right)$. This yields the first order condition:

$$
\frac{1}{\tilde{N}_{i}-I_{i}} \Pi\left(\tilde{N}_{i} ; N_{-i}\right)-\frac{1}{\left(\tilde{N}_{i}-I_{i}\right)} \int_{I_{i}}^{N_{i}} \Pi\left(i ; N_{-i}\right) d i=\frac{1}{\tilde{N}_{i}} \Pi\left(\tilde{N}_{i} ; N_{-i}\right)-\tilde{p}\left(\tilde{N}_{i}, I_{i} ; N_{-i}\right)=0
$$

or $\tilde{p}\left(\tilde{N}_{i}, I_{i} ; N_{-i}\right)=\pi\left(\tilde{N}_{i} ; N_{-i}\right)$; the same outcome as the free entry condition. Thus, all of the above analysis applies equally to closed or open access regimes.

This also highlights something that emerges in standard analyses of access: that simply opening up access to a network is not sufficient to guarantee more competitive outcomes. Even where prices are negotiated, the existence of integrated firms and the incentives of upstream firms to structure networks to achieve productively efficient outcomes, will drive the ultimate market structure.

\subsection{Pre-emptive integration}

Given the impact of integration on market structure, a natural question to consider is whether there is an incentive for pre-emptive integration; designed not only to impact upon the market structure of the constituent network but of other networks as well. The previous set-up allowed the former to a degree (as open versus closed access was irrelevant) but otherwise took all integration and entry decisions across networks as occurring simultaneously.

In the appendix, we demonstrate that there is no incentive for pre-emptive integration. Indeed, if integration could only occur prior to independent entry, in equilibrium upstream firms would not do this. This is because by not integrating an upstream firm commit itself to a larger output ex post. In a Cournot model, this confers a strategic effect. The appendix demonstrates that this outweighs any bargaining advantage from integration. Thus, integrating to have a strategic impact on market structure in a competing network is not worthwhile. Nonetheless, to the extent that integration is possible ex post (or cannot be ruled out), we know that this outcome would not be sustained.

\section{Conclusion}

This paper has demonstrated how bargaining within a network can impact on the intensity of network competition. In the absence of integration, downstream firms will enter until all rents accruing to them are dissipated. Thus, when those firms have some bargaining power then a network will produce more than in a traditional neoclassical case 
where upstream firms have the ability to make take it or leave it offers to downstream firms.

This, however, generates an incentive for upstream firms to integrate (at least partially) so as to mitigate the bargaining position of downstream firms within a network. The end result is that under integration, networks produce less; for this reason, integration has an anti-competitive effects as well as potentially being productively inefficient. This effect occurs regardless of whether access to a network is open (as we model it) or closed; so the existence of such a regime is not an effective policy instrument.

Apart from limiting integration itself, access pricing regulation could clearly modify some of the anti-competitive concerns and indeed the level of integration itself. After all, if integration is undertaken to raise access prices to independent firms, capping those prices will, in turn, reduce the incentive to integrate. More importantly, however, it will commit more rents to be available to downstream firms and encourage their entry. This will stimulate network competition.

Thus, from a policy perspective, many of the recommendations that apply when networks are analysed in a textbook neoclassical manner carry over when, more realistic, intra-network bargaining takes place. At the very least, this suggests that simple objections to the reality of textbook models should be overlooked. On the other hand, the model in this paper provides a tractable method for modelling bargaining outcomes and using this to test the implications of proposed policies.

\section{$6 \quad$ References}

Binmore, K., A. Rubinstein and A. Wolinsky (1986) "The Nash Bargaining Solution in Economic Modelling," RAND Journal of Economics, 17: 176-188.

Chemla, G. (2003) "Downstream Competition, Foreclosure and Vertical Integration," Journal of Economics and Management Strategy, 12: 261-289.

de Fontenay, C.C. and J.S. Gans (2001) "Extending Market Power through Vertical Integration," mimeo, Melbourne.

de Fontenay, C.C. and J.S. Gans (2004a) "Can Vertical Integration by a Monopsonist Harm Consumer Welfare?” International Journal of Industrial Organization, 22: 821-834.

de Fontenay, C.C. and J.S. Gans (2004b) "Vertical Integration in the Presence of Upstream Competition," RAND Journal of Economics, forthcoming.

Hart, O. and J. Tirole (1990) "Vertical Integration and Market Foreclosure," Brookings Papers on Economic Activity, Microeconomics, 1: 205-285.

Kim, J-Y., N-S. Kwark and N-C. Lee (2004) "Revenue-Sharing and Interconnection in the Wireless Internet," mimeo, GRIPS.

Rey, P. and J. Tirole (forthcoming) "A Primer on Foreclosure," Handbook of Industrial Organization, Vol.III. North Holland: Amsterdam. 
Stole, L. and J. Zwiebel (1996a) "Intra-firm Bargaining under Non-binding Contracts," Review of Economic Studies, 63: 375-410.

Stole, L. and J. Zwiebel (1996b) Organizational Design and Technology Choice Under Intrafirm Bargaining," American Economic Review, 86: 195-222.

Williamson, O.E. (1985) The Economic Institutions of Capitalism. New York: Free Press.

\section{$7 \quad$ Technical appendix}

\subsection{Derivation of upstream firm bargaining payoffs}

Let $\tilde{p}_{1}\left(N_{1}, I_{1} ; N_{-1}\right)$ be the negotiated price when the upstream firm deals with $N_{1}$ firms.

$$
\begin{aligned}
& \left(N_{1}-I_{1}\right) \tilde{p}_{1}\left(N_{1}, I_{1} ; N_{-1}\right)+I_{1} \pi_{1}\left(N_{1} ; N_{-1}\right)-\left(N_{1}-1-I_{1}\right) \tilde{p}_{1}\left(N_{1}-1, I_{1} ; N_{-1}\right)-I_{1} \pi_{1}\left(N_{1}-1 ; N_{-1}\right) \\
& \quad=\pi_{1}\left(N_{1} ; N_{-1}\right)-\tilde{p}_{1}\left(N_{1}, I_{1} ; N_{-1}\right) \\
& \Rightarrow \tilde{p}_{1}\left(N_{1}, I_{1} ; N_{-1}\right)=\frac{N_{1}-1-I_{1}}{N_{1}-I_{1}+1} \tilde{p}_{1}\left(N_{1}-1, I_{1} ; N_{-1}\right)-\frac{I_{1}-1}{N_{1}-I_{1}+1} \pi_{1}\left(N_{1} ; N_{-1}\right)+\frac{I_{1}}{N_{1}-I_{1}+1} \pi_{1}\left(N_{1}-1 ; N_{-1}\right) \\
& =\frac{N_{1}-1-I_{1}}{N_{1}+1-I_{1}} \frac{N_{1}-2-I_{1}}{N_{1}-I_{1}} \tilde{p}_{1}\left(N_{1}-2, I_{1} ; N_{-1}\right)+\frac{1}{N_{1}-I_{1}} \pi_{1}\left(N_{1}-1 ; N_{-1}\right)+\frac{N_{1}-1-I_{1}}{N_{1}+1-I_{1}} \frac{I_{1}}{N_{1}-I_{1}} \pi_{1}\left(N_{1}-2 ; N_{-1}\right)-\frac{I_{1}-1}{N_{1}-I_{1}+1} \pi_{1}\left(N_{1} ; N_{-1}\right) \\
& =\ldots \\
& =\frac{1}{\left(N_{1}-I_{1}\right)\left(N_{1}-I_{1}+1\right)} \sum_{i=I_{1}}^{N_{1}} i \pi_{1}\left(i ; N_{-1}\right)-\frac{I_{1}}{N_{1}-I_{1}}\left(\pi_{1}\left(N_{1} ; N_{-1}\right)-\Delta\right) \\
& =\frac{1}{\left(N_{1}-I_{1}\right)\left(N_{1}+1-I_{1}\right)} \sum_{i=I_{1}}^{N_{1}} \prod_{1}\left(i ; N_{-1}\right)-\frac{I_{1}}{N_{1}-I_{1}}\left(\pi_{1}\left(N_{1} ; N_{-1}\right)-\Delta\right)
\end{aligned}
$$

This gives the payoff in (1).

Turning to the continuum case, suppose that there are $N h$ firms, each producing a quantity $h$ of the final good for a cost $\theta h$. In the extreme (as $h$ approaches 0 ), one can derive the results for infinitesimally small firms. In this case, the upstream firm's profits become:

$$
\begin{aligned}
v\left(N_{1}, I_{1}, N_{-1}\right) \equiv & \left(N_{1}-I_{1}\right) \tilde{p}_{1}\left(N_{1}, I_{1} ; N_{-1}\right)+I_{1} \pi\left(N_{1}, N_{-1}\right) \\
& =\frac{1}{N_{1}-I_{1}} \int_{I_{1}}^{N_{1}} \Pi\left(i, N_{-1}\right) d i-\Delta I_{1} \\
& =\frac{1}{N_{1}-I_{1}} \int_{I_{1}}^{N_{1}}\left(P\left(i, N_{-1}\right)-\theta\right) i d i-\Delta I_{1}
\end{aligned} ;
$$

the average of industry profit (as it is in the discrete case).

\subsection{Proof of proposition 1}

As it is fixed, we omit the qualifier $N_{-i}$ in the functions that follow. Note that the free entry condition on $N_{i}$, given any $I_{i} \leq N_{i}$, implies that:

$\Pi\left(\tilde{N}_{i}\right)=\frac{1}{\tilde{N}_{i}-I_{i}} \int_{I_{i}}^{\tilde{N}_{i}} \Pi(i) d i \Leftrightarrow \tilde{p}\left(\tilde{N}_{i}\right)=\pi\left(\tilde{N}_{i}\right)$. 
Using this fact, we can see that:

$$
\begin{gathered}
\frac{d v\left(N_{i}, I_{i}\right)}{d I_{i}}=\frac{\partial v\left(N_{i}, I_{i}\right)}{\partial I_{i}}=-\frac{\Pi\left(I_{i}\right)}{N_{i}-I_{i}}+\frac{1}{\left(N_{i}-I_{i}\right)^{2}} \int_{I_{i}}^{N_{i}} \Pi(i) d i-\Delta=0 \\
\Rightarrow \frac{\Pi\left(\tilde{N}_{i}\right)-\Pi\left(\tilde{I}_{i}\right)}{\tilde{N}_{i}-\tilde{I}_{i}}=\Delta
\end{gathered}
$$

Note that because $\Pi$ is concave, $v$ is concave in $I_{i}$ :

$$
\frac{d^{2} v\left(N_{i}, I_{i}\right)}{d I_{i}{ }^{2}}=\frac{1}{N_{i}-I_{i}}\left[\frac{\Pi\left(N_{i}\right)-\Pi\left(I_{i}\right)}{N_{i}-I_{i}}-\Pi^{\prime}\left(I_{i}\right)\right]<0 .
$$

Therefore the first-order condition implies that $\tilde{I}_{i}=\tilde{N}_{i}=\hat{N}_{i}$ when $\Delta=0$; that $0<\tilde{I}_{i}<\tilde{N}_{i}$ when $\Delta$ is small; and that $\tilde{I}_{i}=0$ when $\Delta \geq \tilde{p}\left(\tilde{N}_{i}(0), 0\right)$ (because in that case $d v / d I<0$ for all $\left.I_{i}\right)$.

\subsection{Proof of strategic substitutability of independent firm numbers}

The conditions for strategic substitutability are:

(5) $\frac{\partial^{2} v}{\partial N_{i} \partial N_{-i}}=\frac{P_{2}\left(N_{i}, N_{-i}\right) N_{i}}{N_{i}-I_{i}}-\frac{1}{\left(N_{i}-I_{i}\right)^{2}} \int_{I_{i}}^{N_{i}} i P_{2}\left(i, N_{-i}\right) d i \leq 0$

(6) $\frac{\partial^{2} v}{\partial I_{i} \partial N_{-i}}=-\frac{P_{2}\left(I_{i}, N_{-i}\right) I_{i}}{N_{i}-I_{i}}+\frac{1}{\left(N_{i}-I_{i}\right)^{2}} \int_{I_{i}}^{N_{i}} i P_{2}\left(i, N_{-i}\right) d i \leq 0$

For the first inequality $((5))$, we take the derivative of the free entry condition with respect to $N_{-i}$.

$$
\begin{aligned}
& \frac{P_{2}\left(N_{j}, N_{-j}\right) N_{j}}{N_{j}-I_{j}}-\frac{1}{\left(N_{j}-I_{j}\right)^{2}} \int_{I_{j}}^{N_{j}} i P_{2}\left(i, N_{-j}\right) d i \\
& \quad \leq \frac{P_{2}\left(N_{j}, N_{-j}\right) N_{j}}{N_{j}-I_{j}}-\frac{1}{\left(N_{j}-I_{j}\right)^{2}} \int_{I_{j}}^{N_{j}} i P_{2}\left(N_{j}, N_{-j}\right) d i \text { as } P_{12} \leq 0 \\
& \quad=\frac{1}{\left(N_{j}-I_{j}\right)^{2}} \int_{I_{j}}^{N_{j}} N_{j} P_{2}\left(N_{j}, N_{-j}\right) d i-\frac{1}{\left(N_{j}-I_{j}\right)^{2}} \int_{I_{j}}^{N_{j}} i P_{2}\left(N_{j}, N_{-j}\right) d i \\
& =\frac{1}{\left(N_{j}-I_{j}\right)^{2}} \int_{I_{j}}^{N_{j}}\left(N_{j}-i\right) P_{2}\left(N_{j}, N_{-j}\right) d i \leq 0
\end{aligned}
$$

And for the second inequality ((6)), 


$$
\begin{aligned}
\frac{\partial^{2} v}{\partial I_{j} \partial N_{-j}} & =\frac{-P_{2}\left(I_{j}, N_{-j}\right) N_{j}}{N_{j}-I_{j}}+\frac{1}{\left(N_{j}-I_{j}\right)^{2}} \int_{I_{j}}^{N_{j}} i P_{2}\left(i, N_{-j}\right) d i \\
& =\frac{-1}{\left(N_{j}-I_{j}\right)^{2}} \int_{I_{j}}^{N_{j}} I_{j} P_{2}\left(I_{j}, N_{-j}\right) d i+\frac{1}{\left(N_{j}-I_{j}\right)^{2}} \int_{I_{j}}^{N_{j}} i P_{2}\left(i, N_{-j}\right) d i \\
& \leq \frac{-1}{\left(N_{j}-I_{j}\right)^{2}} \int_{I_{j}}^{N_{j}} I_{j} P_{2}\left(i, N_{-j}\right) d i+\frac{1}{\left(N_{j}-I_{j}\right)^{2}} \int_{I_{j}}^{N_{j}} i P_{2}\left(i, N_{-j}\right) d i \text { as } P_{12} \leq 0 \\
& \leq \frac{1}{\left(N_{j}-I_{j}\right)^{2}} \int_{I_{j}}^{N_{j}}\left(i-I_{j}\right) P_{2}\left(i, N_{-j}\right) d i \leq 0
\end{aligned}
$$

\subsection{Pre-emptive integration equilibrium}

To consider what happens if upstream firms choose the number of integrated firms prior to any downstream entry, recall that $v\left(N_{i}, I_{i} ; N_{-i}\right)=\left(N_{i}-I_{i}\right) \tilde{p}\left(N_{i}, I_{i} ; N_{-i}\right)+I_{i}\left(P\left(N_{i}+N_{-i}\right)-\theta-\Delta\right)$ and that, under free entry, $\partial v\left(N_{i}, I_{i} ; N_{-i}\right) / \partial N_{i}=0$ in any free entry equilibrium. For simplicity, let's consider a network duopoly. In this case, the incentive for pre-emptive integration will be governed by:

$$
\begin{aligned}
\frac{\partial v\left(\tilde{N}_{1}, I_{1} ; \tilde{N}_{2}\right)}{\partial I_{1}}=- & \tilde{p}\left(\tilde{N}_{1}, I_{1} ; \tilde{N}_{2}\right)+\left(\tilde{N}_{1}-I_{1}\right) \frac{\partial \tilde{p}\left(\tilde{N}_{1}, I_{1} ; \tilde{N}_{2}\right)}{\partial I_{1}}+P\left(\tilde{N}_{1}+\tilde{N}_{2}\right)-\theta-\Delta \\
& \left.+\frac{\partial \tilde{N}_{1}}{\partial I_{1}}\left(\tilde{p}\left(\tilde{N}_{1}, I_{1} ; \tilde{N}_{2}\right)+\left(\tilde{N}_{1}-I_{1}\right) \frac{\partial \tilde{p}\left(\tilde{N}_{1}, I_{1} ; \tilde{N}_{2}\right)}{\partial N_{1}}+I_{1} P^{\prime}\right)\right\}=0 \\
& \left.+\frac{\partial \tilde{N}_{2}}{\partial I_{1}}\left(\left(\tilde{N}_{1}-I_{1}\right) \frac{\partial \tilde{p}\left(\tilde{N}_{1}, I_{1} ; \tilde{N}_{2}\right)}{\partial N_{2}}+I_{1} P^{\prime}\right)\right\} \geq 0
\end{aligned}
$$

where the second term is zero by the free entry condition and the final term is positive because increased integration by $U 1$ causes a reduction in entry on $U 2$ 's network that, in turn, cases a reduction in the price paid to $U 1$ 's downstream affiliates as:

$$
\frac{\partial \tilde{p}\left(\tilde{N}_{1}, I_{1} ; \tilde{N}_{2}\right)}{\partial \tilde{N}_{2}}=\frac{1}{\left(\tilde{N}_{1}-I_{1}\right)^{2}} \int_{I_{1}}^{\tilde{N}_{1}} i P^{\prime}\left(i+\tilde{N}_{2}\right) d i-\frac{I_{1}}{\tilde{N}_{1}-I_{1}} P^{\prime}\left(\tilde{N}_{1}+\tilde{N}_{2}\right) \leq 0 \text {. }
$$

Thus, integration has two effects. The first, as before, is a bargaining effect; increased integration raises the supply price paid to the upstream firm. The second is a strategic effect; increased integration reduces entry (and output) by the other network.

Given the complexity of the effects, the full equilibrium outcomes are best considered for the linear demand case. In this situation, holding $\left(I_{1}, I_{2}\right)$ fixed, the stage 2 equilibrium in entry has:

$$
\tilde{N}_{1}=\frac{1}{7}\left(3\left(A+2 I_{2}-\theta\right)-8 I_{1}\right)
$$




$$
\tilde{N}_{2}=\frac{1}{7}\left(3\left(A+2 I_{1}-\theta\right)-8 I_{2}\right)
$$

Thus, an increase in $I_{1}$ leads, ceteris paribus, to a fall in $\tilde{N}_{1} / \tilde{N}_{2}$; integration puts the network at a strategic disadvantage as the bargaining effect outweighs the strategic effect. Significantly, however, an increase in integration leads to a fall in industry output $\left(\tilde{N}_{1}+\tilde{N}_{2}\right)$. Indeed, looking at $U 1$ 's profits,

$$
\frac{\partial v\left(\tilde{N}_{1}, I_{1} ; \tilde{N}_{2}\right)}{\partial I_{2}}=\frac{1}{49}\left(12\left(A+2 I_{2}-\theta\right)-4 I_{1}\right)>0 .
$$

$$
\frac{\partial v\left(\tilde{N}_{1}, I_{1} ; \tilde{N}_{2}\right)}{\partial I_{1} \partial I_{2}}=-\frac{4}{49}<0 .
$$

Thus, integration by $U 2$ raises $U 1$ 's profits but integration decisions are strategic substitutes; that is, an increase in integration by $U 2$ will cause $U 1$ to reduce its number of integrated units. So each upstream firm would prefer more integration by the other firm and would free ride off this integration by reducing its own number of integrated units.

This free rider problem turns out to have an extreme outcome. Indeed, it is easy to demonstrate that in this situation, neither firm wishes to integrate. To see this, note that:

$$
\frac{\partial v\left(\tilde{N}_{1}, I_{1} ; \tilde{N}_{2}\right)}{\partial I_{1}}=-\frac{1}{49}\left(2(A-\theta)+32 I_{1}+4 I_{2}\right)-\Delta<0 .
$$

Thus, in equilibrium, $\tilde{I}_{1}=\tilde{I}_{2}=0$, so that the outcome is as in the no integration case. 